\title{
The New Low-Profile WEB 17 System for Treatment of Intracranial Aneurysms: First Clinical Experiences
}

\author{
(D).B.T. van Rooij, (DJ.P. Peluso, (D) M. Sluzewski, DH.G. Kortman, and (D)W.J. van Rooij
}

\begin{abstract}
BACKGROUND AND PURPOSE: The Woven EndoBridge (WEB) is an intrasaccular flow diverter intended to treat wide-neck aneurysms. The latest generation WEBs needed a 0.021-inch microcatheter in the small sizes. Recently, a lower profile range of WEBs compliant with a 0.017 -inch microcatheter (WEB 17) has been introduced. We present the first clinical results of treatment of both ruptured and unruptured aneurysms with the WEB 17.
\end{abstract}

MATERIALS AND METHODS: Between December 2016 and September 2017, forty-six aneurysms in 40 patients were treated with the WEB 17. No supporting stents or balloons were used. Twenty-five aneurysms were ruptured (54\%). There were 6 men and 34 women (mean age, 62 years; median, 63 years; range, $46-87$ years). The mean aneurysm size was $4.9 \mathrm{~mm}$ (median, $5 \mathrm{~mm}$; range, 2-7 mm).

RESULTS: There were 2 thromboembolic procedural complications without clinical sequelae and no ruptures. The overall permanent procedural complication rate was $0 \%$ (0 of $40 ; 97.5 \% \mathrm{Cl}, 0 \%-10.4 \%$ ). Imaging follow-up at 3 months was available in 33 patients with 39 aneurysms ( $97.5 \%$ of 40 eligible aneurysms). In 1 aneurysm, the detached WEB was undersized and the remnant was additionally treated with coils after 1 week. This same aneurysm reopened at 3 months and was again treated with a second WEB. One other aneurysm showed persistent WEB filling at 3 months. Complete occlusion was achieved in 28 of 39 aneurysms (72\%), and 9 aneurysms (23\%) showed a neck remnant.

CONCLUSIONS: The WEB 17 is safe and effective for both ruptured and unruptured aneurysms. The WEB 17 is a valuable addition to the existing WEB size range, especially for very small aneurysms.

ABBREVIATIONS: WEB = Woven EndoBridge; SL = single layer; SLS = single-layer sphere

$\mathbf{R}_{\mathrm{w}}^{\mathrm{e}}$ ecently, the self-expanding intra-aneurysmal flow disruptor Woven EndoBridge (WEB; Sequent Medical, Aliso Viejo, California) device has been developed primarily for the treatment of wide-neck aneurysms without the need for supporting devices and concomitant dual-antiplatelet therapy.

The first clinical results of the WEB device showed good safety and efficacy profiles. Most of the published series comprised wideneck, unruptured aneurysms. ${ }^{1-14}$ The first-generation WEBs required 0.027- to 0.033-inch microcatheters for delivery. In 2015, the WEB was redesigned for a 0.021 -inch delivery microcatheter (WEB 21) in sizes ranging from 4 to $7 \mathrm{~mm}$.

Received December 27, 2017; accepted after revision January 31, 2018.

From the Department of Radiology (S.B.T.v.R.), Noordwest Ziekenhuisgroep, Alkmaar, the Netherlands; and Department of Radiology (J.P.P., M.S., H.G.K., W.J.v.R.), Elisabeth-Tweesteden Ziekenhuis, Tilburg, the Netherlands.

Please address correspondence to S.B.T. van Rooij, MD, Dept of Radiology, Noord west Ziekenhuisgroep, Wilhelminalaan 12, 1815JD Alkmaar, the Netherlands; e-mail: s.b.t.rooij@gmail.com

三 Indicates article with supplemental on-line table.

http://dx.doi.org/10.3174/ajnr.A5608
A new-generation low-profile WEB was introduced in clinical practice in December 2016. This system is compatible with a 0.017 -inch microcatheter (WEB 17). Fewer wires were used to construct the device to achieve this lower profile. In benchmark studies, the flow-diverting effect seemed equal to that of the WEB 21 system (MicroVention, Bill Patterson, personal communication, October 27, 2016). The WEB 17 is intended for small aneurysms and comes in sizes of 3-7 $\mathrm{mm}$.

In this study, we present the first clinical results of 46 ruptured and unruptured small aneurysms treated with the new WEB 17 system.

\section{MATERIALS AND METHODS WEB Device}

The WEB device is a self-expanding, oblong or spheric braid of platinum-cored nitinol wires intended to implant inside the aneurysmal sac. The device is electrothermally detachable and is introduced through a microcatheter. In 2010, the device was introduced as the WEB dual-layer, with a second nitinol mesh placed at the bottom inside the primary braid to increase metal 
coverage at the neck of the aneurysm. In 2015, the lower profile WEB single-layer (SL) and WEB single-layer sphere (SLS) replaced this high-profile dual-layer version. The WEB-SL has an oblong shape, whereas the SLS version is more spheric. The WEB 21 comes in diameters ranging from 4 (144 wires) to 11 $\mathrm{mm}$ (216 wires) in $1-\mathrm{mm}$ increments. The lengths of the SL version range from 3 to $7 \mathrm{~mm}$. The length of the SLS version is $1.6 \mathrm{~mm}$ less than its diameter. WEB devices in diameters of 4-7 $\mathrm{mm}$ are compatible with a 0.021 -inch microcatheter, while the 8- and 9-mm diameter needs a 0.027 -inch microcatheter. The largest sizes of $10-11 \mathrm{~mm}$ go through a 0.033 -inch microcatheter. The VIA microcatheter (Sequent Medical) is available in these different sizes and is specifically designed for the delivery of the WEB device.

Recently, the new low-profile WEB 17 system was introduced. The WEB 17 is especially designed for (very) small aneurysms. This system can be delivered through a 0.017 -inch microcatheter. The WEB 17 comes in new smaller sizes starting at $3 \mathrm{~mm}$ and more shallow devices of 2-mm height for WEB sizes of 3-5 $\mathrm{mm}$. The WEB 17 has fewer platinum-cored nitinol wires than the WEB 21 (72-108 versus 144) but a similar metal coverage at the neck (57\%-59\% versus 59\%-62\%). The WEB 17 SL is available in diameters ranging from $2 \times 3 \mathrm{~mm}$ to $7 \times 4 \mathrm{~mm}$, and the WEB 17 SLS, in diameters of 4-7 $\mathrm{mm}$. In the 4- to 7 - $\mathrm{mm}$ range, there is overlap with the WEB 21 system, both in SL and SLS shapes.

\section{General Indications in This Study}

Treatment of patients with both ruptured and unruptured aneurysms is primarily endovascular in our institution. Patients with ruptured aneurysms are treated within 24 hours after admission. Patients with unruptured aneurysms are discussed in a weekly joint meeting with neurologists, neurosurgeons, and neuroradiologists.

The WEB system has been used for endovascular treatment in our institution since early 2015 . We started using the WEB for wide-neck bifurcation aneurysms to replace stents, especially in ruptured aneurysms. Encouraging results led us to expand the indication for the WEB to all aneurysms suitable for the device, regardless of location or neck size. ${ }^{15}$

With the introduction of the WEB 17, we considered using this WEB in all small aneurysms judged suitable for the device. In general, only shallow aneurysms (height/dome ratio $\leq 0.5$ ) and some aneurysms with vessels coming from the sac were treated otherwise.

\section{WEB 17 Embolization Technique}

Embolization was performed on a biplane angiographic system (AlluraClarity; Philips Healthcare, Best, the Netherlands) with the patient under general anesthesia by 3 interventional neuroradiologists with 26, 24, and 12 years of experience (W.J.v.R., M.S., J.P.P.). In unruptured aneurysms, $5000 \mathrm{U}$ of heparin was administered as a bolus at the start of the procedure. In ruptured aneurysms, no anticoagulation was performed except the heparin in the pressure bags used for flushing (1000 U/L).

The required WEB is determined from a $3 \mathrm{D}$ angiographic dataset with calibrated distance measurements. Width, height, and

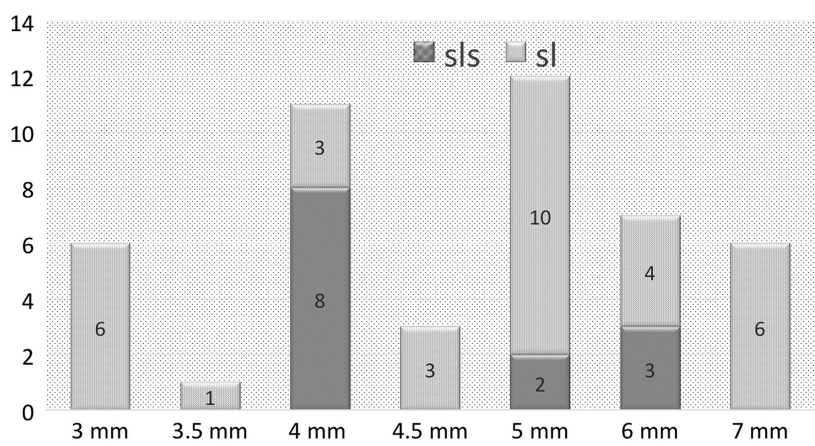

FIG 1. WEB sizes and shapes used in 46 aneurysms treated with WEB 17.

neck size of the aneurysm are measured in 2 orthogonal planes. The WEB is slightly oversized to ensure a stable position inside the aneurysm, and $1 \mathrm{~mm}$ was added to the average width of the aneurysm. To correct for increased height caused by horizontal compression, we deducted $1 \mathrm{~mm}$ from the average height of the aneurysm $(+1 /-1$ rule).

A VIA 17 microcatheter was placed inside the aneurysmal fundus. The microcatheter could be steam-shaped, depending on vessel geometry. Once it was inside the aneurysm, gentle forward pushing and simultaneous withdrawal of the microcatheter slowly deployed the WEB. After deployment, the position of the WEB device was evaluated with fluoroscopy and an additional angiographic run, sometimes including 3D angiography. When the position of the WEB 17 was considered correct, the device was detached and the catheters were removed.

\section{Data Collection and Angiographic Follow-Up}

Patient demographics and treatment and aneurysm characteristics were recorded and retrospectively reviewed. Clinical follow-up was classified with the Modified Rankin Scale at 3-month follow-up. Angiographic follow-up was scheduled at 3 months, and 3T MRA follow-up, at 6 and 12 months according to a previously published protocol. ${ }^{16}$ Angiographic results were classified as complete occlusion, neck remnant, or aneurysm remnant.

Categoric variables were expressed as frequencies or percentages with 95\% CIs. Quantitative variables were expressed with descriptive statistics.

\section{RESULTS \\ Patients}

Between December 19, 2016, and September 19, 2017, forty patients with 46 aneurysms were treated with the WEB 17 system. Three patients had 2 aneurysms, and 1 patient had 4 aneurysms. Of 46 aneurysms, 25 had ruptured (54\%). There were 34 women and 6 men with a mean age of 62 years (median, 63 years; range, 46-87 years). Patient and aneurysm characteristics are shown in the On-line Table.

Aneurysm location was the anterior communicating artery in 17 patients; the middle cerebral artery in 13; the posterior communicating artery in 7; the pericallosal artery in 3; the basilar tip in 3; and the anterior choroidal artery, carotid tip, and superior cerebellar artery each in 1 . The mean aneurysm size was $4.9 \mathrm{~mm}$ (median, $5 \mathrm{~mm}$; range, 2-7 mm). WEB sizes and shapes used are shown in Fig 1. 


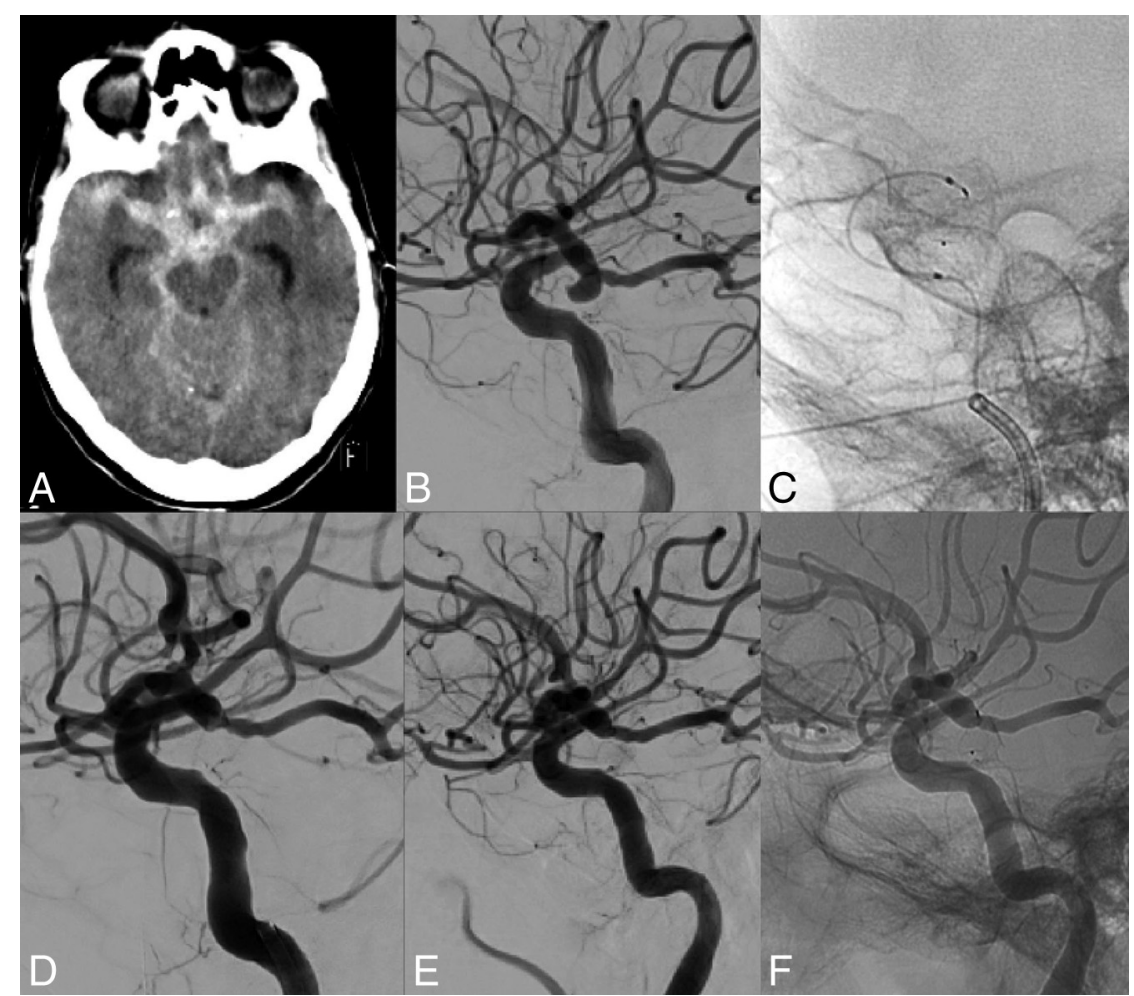

FIG 2. A 71-year-old woman (patient 32) with a ruptured posterior communicating artery aneurysm. $A, C T$ scan shows diffuse subarachnoid blood. $B$, Lateral right internal carotid angiogram reveals a small posterior communicating artery aneurysm pointing downward. C, VIA 17 in a hairpin configuration after deployment of the WEB $17 \mathrm{SLS} 6 \mathrm{~mm}$ inside the aneurysm. D, Immediate aneurysm occlusion after WEB 17 placement. $E$ and $F$. Three-month follow-up angiogram demonstrates persistent complete aneurysm occlusion.

\section{Initial Results and Complications}

After WEB placement with sealing of the aneurysm neck, the position of the WEB inside the aneurysm was judged good in 45 of 46 aneurysms without filling of aneurysm remnants. In 1 patient (patient 10), the WEB was undersized, but this was only noticed after detachment. Follow-up angiography after 1 week showed an aneurysm remnant that was then occluded with coils.

There were 2 thromboembolic complications, both in patients with a ruptured anterior communicating artery aneurysm. In a 62year-old man (patient 25), there was a thromboembolic occlusion of the carotid tip during diagnostic catheterization before WEB placement. This thrombus could be removed with thrombosuction. After the procedure, he had paresis of the left arm that resolved the next day. The other patient was a 54-year-old woman (patient 11) with an ICA dissection during diagnostic angiography followed by thrombotic occlusion of the left A2. During WEB placement, the thrombus migrated distally. After sealing of the aneurysm, she was treated with tirofiban infusion, and she woke up without a deficit.

There were no procedural ruptures. The overall permanent complication rate was $0 \%$ ( 0 of $40 ; 97.5 \%$ CI, $0 \%-10.4 \%$ ).

\section{Clinical and Imaging Follow-Up}

All 15 patients with 21 unruptured aneurysms treated with WEB 17 remained clinically intact. In 25 patients with a ruptured aneurysm, no early or late rebleeds occurred. Clinical follow-up of these 25 patients was as follows: Six died due to sequelae of SAH (mRS 6), 1 was dependent (mRS 4), 5 had some disability but were independent (mRS 2 and 3 ), and 13 were independent (mRS 0 and 1 ).
Six patients died of SAH during hospital admission. Of the 34 surviving patients, 1 refused follow-up angiography. Of the remaining 33 patients, 31 with 37 aneurysms had 3 month-angiographic follow-up. Two patients had MRA follow-up at 3 months. Thus, imaging follow-up at 3 months was available in 33 patients with 39 aneurysms ( $97.5 \%$ of 40 eligible aneurysms).

Two aneurysms (5.1\%) were incompletely occluded: Patient 10 had early additional treatment of the WEB 17treated ruptured aneurysm. At 3-month follow-up, the aneurysm had reopened and was again retreated, now with a WEB 17. One other aneurysm (patient 33) showed persistent WEB filling at 3 months.

Complete occlusion was achieved in 28 of 39 aneurysms (72\%), and 9 aneurysms (23\%) showed a neck remnant.

Extended MRA follow-up at 6 months was available in 22 aneurysms (Online Table). The occlusion status of those aneurysms was not changed during the time interval.

\section{DISCUSSION}

Our preliminary clinical experience with the new low-profile WEB 17 system demonstrates an encouraging safety and efficacy profile. No permanent procedural complications occurred in 40 patients, and no rebleeds occurred in 25 patients with a ruptured aneurysm. Aneurysm occlusion at follow-up was satisfactory with $95 \%$ adequate occlusion at 3 months with only 1 aneurysm retreated. Two procedural thromboembolic complications occurred that could be resolved with thrombosuction and tirofiban use and remained without clinical sequelae.

Comparison with other studies is hampered by several factors. The small sample size of this study keeps confidence levels wide. Both ruptured and unruptured aneurysms were included. All aneurysms were small ( $\leq 7 \mathrm{~mm}$ ) because the maximum size of the WEB 17 is $7 \mathrm{~mm}$. Because larger aneurysm size is a well-known risk factor for reopening with time, our study only comprising small aneurysms has a bias toward better results at follow-up.

Our first results with the WEB 17 are in line with other studies using previous generations of the WEB or coils to treat intracranial aneurysms. ${ }^{1-14}$ In a meta-analysis by Asnafi et al, 15 uncontrolled series were included, totaling 565 patients with 588 aneurysms treated with the WEB, of which 127 were ruptured. Initial complete and adequate occlusion rates were $27 \%$ and $59 \%$, respectively. Midterm complete and adequate occlusion rates after a median of 7 months were $39 \%$ and $85 \%$, respectively. Perioperative morbidity and mortality rates were $4 \%$ and $1 \%$, respectively. Midterm adequate occlusion rates for ruptured aneurysms were $85 \%$ compared with $84 \%$ for unruptured aneurysms. Both patients with ruptured aneu- 


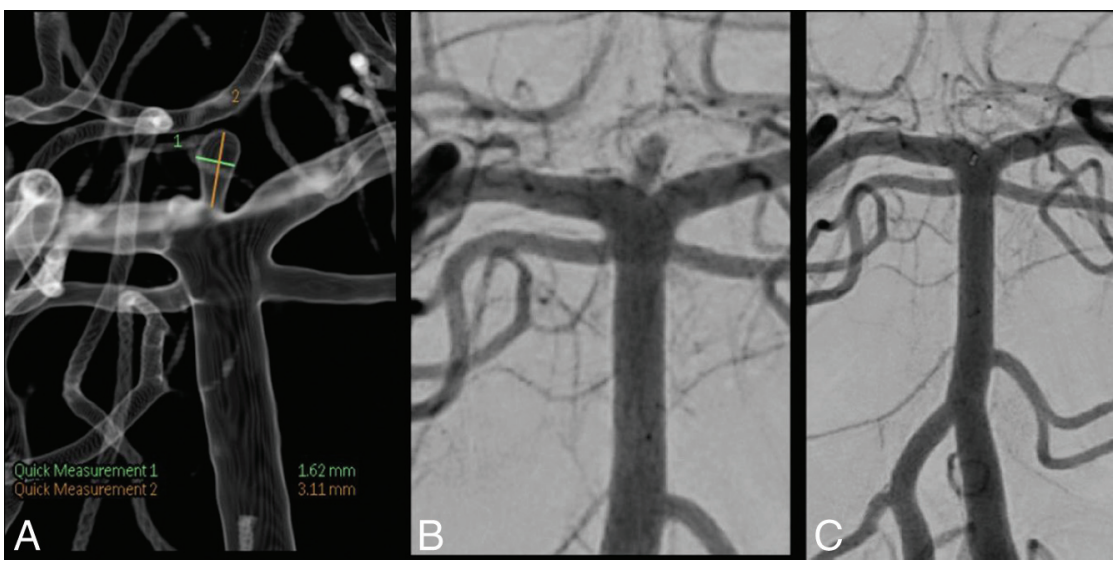

FIG 3. A 62-year-old woman (patient 36) with an unruptured small basilar tip aneurysm. A, Basilar tip aneurysm measuring $1.6 \times 3.1 \mathrm{~mm}$. B, Immediately after placement of WEB $17(2 \times 3 \mathrm{~mm})$. C, Complete occlusion at 3 months follow-up.

rysms and patients with unruptured aneurysms had perioperative morbidity rates of $2 \%$. Our results of $95 \%$ adequate occlusion at 3 months are in the same range as in this meta-analysis, and complication rates were on the same order.

Subjectively, handling of the WEB 17 is smoother than the WEB 21. The WEB 17 is easily introduced through the VIA 17 microcatheter with very low resistance. Unsheathing and deploying the WEB 17 in the aneurysm is smooth, and recapturing is easy with only a little pulling force needed. Because the WEB 17 has fewer and thinner wires than the WEB 21 with weaker memory forces, deployment may sometimes be incomplete, especially when the WEB is angled or rotated. The softer WEB structure makes deformation by pushing or pulling forces easier than with the WEB 21. On the other hand, navigation with the VIA 17 is simpler than with the more rigid VIA 21 microcatheter. The VIA 17 is advantageous in complicated anatomy such as navigating a sharp-angled carotid artery-A1 transition or in situations where a "hairpin" position of the microcatheter is required such as in some posterior communicating artery aneurysms (Fig 2). With very small aneurysms of 2-3 mm, use of the WEB 17 in the smallest sizes is imperative (Fig 3).

There is overlap in WEB 17 and 21 in the 4- to 7-mm sizes. When a WEB in this size range is required to treat the aneurysm, the operator has a choice between the 2 systems. The WEB 21 system is more stable during WEB deployment, and the WEB 21 has better memory forces. Instead, the WEB 17 system can be navigated more easily in complicated anatomy. These considerations may help the operator in the choice between the 2 systems.

Our study confirms the conceptual proof of the WEB 17 system. Despite the construction with fewer platinum-cored nitinol wires, flow disruption proved excellent, with only 1 aneurysm showing persistent WEB filling at follow-up. Adequate aneurysm occlusion was obtained in $95 \%$ of aneurysms with imaging follow-up, and no rebleeds occurred in the 25 ruptured aneurysms during clinical followup. There were no permanent complications.

Recently, a new intrasaccular flow disruptor has become available in clinical practice (Medina Embolization Device; Medtronic, Minneapolis, Minnesota). This device combines the design of a detachable coil and that of an intrasaccular flow-disruption device. For now, clinical experience is limited, and the first results are encouraging. ${ }^{17}$
Our study has several limitations. The limited sample size makes confidence intervals wide and encumbers comparison with other studies. Patients were not consecutive but were selected on the basis of the anticipated suitability of the aneurysm for the WEB 17. We, not a core lab, established aneurysm occlusion at follow-up. The follow-up period was limited; this drawback precludes conclusions of effectiveness at mid- and long term. The essential choice of small and very small aneurysms is a bias toward better results at follow-up. Strong points of the study are the complete clinical and almost complete imaging follow-up.

\section{CONCLUSIONS}

The new low-profile WEB 17 system is a welcome addition to the existing WEB range. Indications expand to very small aneurysms. The supple VIA 17 microcatheter navigates well in situations with difficult vascular geometry. In the 4- to 7-mm size, there is overlap of the WEB 17 and 21, and the operator may choose between the 2 systems depending on patient-specific factors.

Disclosures: S.B.T. van Rooij-RELATED: Grant: MicroVention, Comments: support of salary and travel expenses directly related to the study. * W.J. van Rooij-RELATED: Consulting Fee or Honorarium: MicroVention; Support for Travel to Meetings for the Study or Other Purposes: MicroVention. *Money paid to the institution.

\section{REFERENCES}

1. Armoiry X, Turjman F, Hartmann DJ, et al. Endovascular treatment of intracranial aneurysms with the WEB device: a systematic review of clinical outcomes. AJNR Am J Neuroradiol 2016;37:868-72 CrossRef Medline

2. Sivan-Hoffmann R, Gory B, Riva R, et al. One-year angiographic follow-up after WEB-SL endovascular treatment of wide-neck bifurcation intracranial aneurysms. AJNR Am J Neuroradiol 2015;36: 2320-24 CrossRef Medline

3. Lawson A, Goddard T, Ross S, et al. Endovascular treatment of cerebral aneurysms using the Woven EndoBridge technique in a single center: preliminary results. J Neurosurg 2017;126:17-28 CrossRef Medline

4. Lawson A, Molyneux A, Sellar R, et al. Safety results from the treatment of 109 cerebral aneurysms using the Woven EndoBridge technique: preliminary results in the United Kingdom. J Neurosurg 2018;128:144-53 CrossRef Medline

5. Gherasim DN, Gory B, Sivan-Hoffmann R, et al. Endovascular treatment of wide-neck anterior communicating artery aneurysms using WEB-DL and WEB-SL: short-term results in a multicenter study. AJNR Am J Neuroradiol 2015;36:1150-54 CrossRef Medline

6. Fiorella D, Molyneux A, Coon A, et al; WEB-IT Study Investigators. Demographic, procedural and 30-day safety results from the WEB Intra-saccular Therapy Study (WEB-IT). J Neurointerv Surg 2017;9: 1191-96 CrossRef Medline

7. Asnafi S, Rouchaud A, Pierot L, et al. Efficacy and safety of the Woven EndoBrigde (WEB) device for the treatment of intracranial aneurysms: a systemic review and meta-analysis. AJNR Am J Neuroradiol 2016;37:2287-92 CrossRef Medline

8. Pierot L, Moret J, Turjman F, et al. WEB treatment of intracranial aneurysms: clinical and anatomic results in the French Observatory. AJNR Am J Neuroradiol 2016;37:655-59 CrossRef Medline 
9. Pierot L, Spelle L, Molyneux A, et al. Clinical and anatomical follow-up in patients with aneurysms treated with the WEB device: 1-year follow-up report in the cumulated population of 2 prospective, multicenter series (WEBCAST and French Observatory). Neurosurgery 2016;78:133-41 CrossRef Medline

10. Pierot $\mathrm{L}$, Costalat V, Moret J, et al. Safety and efficacy of aneurysm treatment with WEB: results of the WEBCAST study. J Neurosurg 2016;124:1250-56 CrossRef Medline

11. Clajus C, Strasilla C, Fiebig T, et al. Initial and mid-term results from 108 consecutive patients with cerebral aneurysms treated with the WEB device. J Neurointerv Surg 2017;9:411-17 CrossRef Medline

12. Pierot L, Gubucz I, Buhk JH, et al. Safety and efficacy of aneurysm treatment with the WEB: results of the WEBCAST 2 study. AJNR Am J Neuroradiol 2017;38:1151-55 CrossRef Medline

13. Liebig T, Kabbasch C, Strasilla C, et al. Intrasaccular flow disruption in acutely ruptured aneurysms: a multicenter retrospective review of the use of the WEB. AJNR Am J Neuroradiol 2015;36:1721-27 CrossRef Medline

14. Popielski J, Berlis A, Weber W, et al. Two-center experience in the endovascular treatment of ruptured and unruptured aneurysms using the WEB device: a retrospective analysis. AJNR Am J Neuroradiol 2018;39:111-17 CrossRef Medline

15. van Rooij SB, van Rooij WJ, Peluso JP, et al. WEB treatment of ruptured intracranial aneurysms: a single-center cohort of 100 aneurysms. AJNR Am J Neuroradiol 2017;38:2282-87 CrossRef Medline

16. Majoie CB, Sprengers ME, van Rooij WJ, et al. MR angiography at 3T versus digital subtraction angiography in the follow-up of intracranial aneurysms treated with detachable coils. AJNR Am J Neuroradiol 2005;26:1349-56 Medline

17. Sourour NA, VandePerre S, Maria FD, et al. Medina embolization device for the treatment of intracranial aneurysms: safety and angiographic effectiveness at 6 months. Neurosurgery 2018;82:155-62 CrossRef Medline 